\title{
Sintesis Asam-Asam Lemak Hidroksamik dari Minyak Kelapa Menggunakan Lipase sebagai Katalis
}

\author{
Dedy Suhendra*) dan Erin Ryantin Gunawan \\ Program Studi Kimia, Fakultas Matematika dan Ilmu Pengetahuan Alam, Universitas Mataram, Mataram 83125 \\ Diterima 14-12-2009 Disetujui 14-06-2011
}

\begin{abstract}
Fatty hydroxamic acids (FHAs) have been successfully synthesized from coconut oil by a one-step lipase catalyzed reaction. FHAs are the acids that are based on fatty acids. Their hydrophobicity can be use for some applications such as surfactant and metal ions extraction from aqueous media. This paper describes enzymatic synthesis of FHAs from coconut oil by reacting hydroxylamine with the substrate catalyzed by a lipase. The lipase used was Lipozyme, a commercially lipase of Mucor meihe fixed on a polymer anion exchange resin. The use of immobilized lipase as the catalyst for the preparation reaction provides an easy isolation of the enzyme from the products and other components in the reaction mixture. In addition, it also allows the reaction to be carried out under mild conditions, which reduces the reaction's side products. The optimum preparation conditions obtained were as follows; the reaction temperature was $30^{\circ} \mathrm{C}$, the reaction time was $30 \mathrm{~h}$, the ratio of coconut oil : lipozyme ( $\mathrm{g}: \mathrm{g}$ ) was 29.5 , and the ratio of hydroxylamine : coconut oil (mmol : mmol) was 6 . The solvent used was hexane. The purified products were characterized by qualitative test, such as FTIR spectroscopy and HPLC.
\end{abstract}

Keywords: coconut oil, enzymatic synthesis, fatty hydroxamic acids, lipase

\section{ABSTRAK BERBAHASA INDONESIA}

Asam-asam lemak hidroksamik (ALH) telah berhasil disintesis dari minyak kelapa menggunakan lipase sebagai katalis. ALH adalah asamasam turunan asam lemak, oleh karena itu sifat hidrofobisitasnya dapat digunakan untuk beberapa aplikasi seperti surfaktan dan ekstraksi ion-ion logam dari media larutan air. Tulisan ini menggambarkan sintesis ALH dari minyak kelapa secara enzimatis dengan mereaksikan hidroksilamina dengan substrat menggunakan katalis lipase. Lipase yang digunakan adalah lypozyme, yaitu suatu lipase komersial dari Rhizomисоr miehei yang diimmobilisasi ke dalam resin penukar anion. Penggunaan lipase yang diimobilisasi sebagai katalis disebabkan kemudahan isolasi produk dari komponen-komponen lain dalam campuran reaksi. Lypozyme juga memungkinkan reaksi berlangsung pada suhu rendah yang tentunya mengurangi resiko terbentuknya produk samping. Kondisi-kondisi optimum yang diperoleh adalah suhu reaksi $30^{\circ} \mathrm{C}$, waktu reaksi 30 jam, rasio minyak kelapa : lypozyme (g: g) adalah $40: 1$ dan rasio hidroksilamina : minyak kelapa (mmol : mmol) adalah 2,21 : 1. Pelarut yang digunakan adalah heksana. Produk yang telah dimurnikan telah karakterisasi menggunakan tes kualitatif, spektroskopi infra merah dan CHN elemental analysis.

Keywords: asam lemak hidroksamik, coconut oil, enzymatic Synthesis, lipase

\section{PENDAHULUAN}

Asam-asam hidroksamik, hydroxamic acids, merupakan agen pengkelat (chelating agent) turunan hidroksilamina dan asam karboksilat, oleh karena itu asam hidroksamik juga disebut $N$-hidroksi amida karboksilat dengan rumus umum R-CO-NHOH. Akhir-akhir ini, asam hidroksamik dan turunannya mendapat perhatian serius dari banyak peneliti yang disebabkan oleh aktivitas biologinya, seperti pemacu pertumbuhan, antibiotik, antifungi (Kurzak et al. 1992), inhibitor enzim (Anandan et al. 2007), anti tumor (Holmes et al. 2001), pencegah korosi besi (Deng et al. 2008) dan anti oksidan (Liu et al. 2008). Kompleks antara asam hidroksamik dengan berbagai ion logam banyak digunakan untuk keperluan kimia analitik, yaitu sebagai reagen pada penentuan logam secara gravimetri dan spektrometri

\footnotetext{
*Telp: +6281339660976

e-mail: dedysuhendra@unram.ac.id
}

(Pacco 2008), sebagai sensor kimia dalam penentuan logam-logam renik (Isha et al. 2007), sebagai kolektor untuk unsur-unsur tanah jarang (Agrawal \& Kaur 1999), dan untuk mengekstrak ion-ion logam dari larutan (Suhendra et al. 2005a \& 2005b).

Kegunaan yang sangat beragam dari asam-asam hidroksamik dan kebutuhan akan chelating agent untuk keperluan penelitian dan pengajaran dalam bidang kimia analitik yang tinggi, tidak dibarengi dengan ketersediaan bahan yang mencukupi. Bahkan, kajian literatur yang dilakukan, menunjukkan bahwa telah banyak penelitian untuk mensintesis asam-asam hidroksamik dari berbagai bahan dasar, dan bahkan banyak yang sudah tersedia sebagai produk komersial. Akan tetapi, sampai saat ini belum ditemukan produk komersial untuk asam-asam hidroksamik rantai panjang. 
Untuk kegunaan pengajaran dalam bidang kimia analitik, utamanya pada pemisahan atau pemurnian ion logam, banyak diperlukan chelating agent. Akan tetapi, akhir-akhir ini, harga bahan kimia terutama chelating agent sangat mahal, sehingga perlu dipikirkan untuk mencari chelating agent yang murah dan dapat disiapkan dari bahan dasar yang ada di sekitar. Ada dua cara pemisahan logam atau ekstraksi logam dari larutan menggunakan chelating agent, yaitu ekstraksi pelarut dan imobilisasi chelating agent ke dalam polimer pendukung (polymer support) yang tidak polar. Untuk keperluan tersebut, maka diperlukan chelating agent yang mempunyai sifat hidrofobik dan hidrofilik sekaligus. Jika dilihat dari gugus fungsinya, asam hidroksamik bersifat polar (hidrofilik), oleh karena itu diperlukan gugus alkil rantai menengah sampai panjang agar juga bersifat hidrofobik.

Komponen utama minyak nabati adalah triasilgliserol, yaitu ester dari asam-asam lemak dengan gliserol. Sintesis asam-asam hidroksamik menggunakan minyak nabati sebagai precursor telah dilakukan dengan menggunakan minyak kedelai (soybean oil ) (Servat et al. 1990), dan minyak olein kelapa sawit (palm olein) (Suhendra et al. 2005a). Komponen utama dari minyak kedelai adalah asam linoleat $(54 \%)$, sedangkan komponen utama minyak olein kelapa sawit adalah asam palmitat yaitu 37\% (Zamora 2005). Ditinjau dari panjang rantai asam lemak, maka komponen utama dari kedua minyak tersebut adalah asam lemak rantai panjang. Sebenarnya untuk keperluan ekstraksi logam dalam larutan, kedua jenis minyak ini sudah memenuhi syarat sebagai bahan dasar sintesis asam hidroksamik, namun akhir-akhir ini, harga kedua komoditi ini cukup mahal. Oleh karena itu, pada penelitian ini digunakan minyak kelapa sebagai bahan dasar sintesis chelating agent asam hidroksamik. Dengan pertimbangan; bahan dasar yang relatif lebih murah, ketersediaan yang melimpah, dan kandungan asam lemak utamanya adalah asam laurat yaitu 47\% (Zamora 2005), yang merupakan asam lemak rantai menengah.

Sintesis asam-asam hidroksamik dapat dilakukan dengan dua metode, yaitu secara kimiawi dan secara enzimatik. Cara pertama dilakukan dalam suasana basa dan suhu yang cukup tinggi. Untuk sintesis asam hidroksamik dari minyak nabati, maka cara ini kurang tepat karena terdapat asam lemak penyusun minyak yang mempunyai ikatan rangkap. Pada suasana basa dan suhu yang tinggi, maka ikatan rangkap tersebut dapat teroksidasi. Cara kedua merupakan cara yang dirasa paling tepat. Hal ini disebabkan cara enzimatik bekerja dalam suasana netral dan suhu rendah, disamping itu, ramah lingkungan serta enzim yang digunakan dapat dipergunakan kembali. Penelitian ini difokuskan pada sintesis asam-asam lemak hidroksamik (ALH) dari minyak kelapa yang dikatalisis oleh enzim lipase.

\section{BAHANDANMETODE}

Semua bahan kimia yang digunakan pada penelitian ini berderajat analytical grade; hidroksilamina hidroklorida, dan natrium hidroksida, metanol, n-heksana kesemuanya produk dari Merck, Jerman. Enzim lipase yang digunakan adalah lipozim produksi dari Novo Nordisk (Denmark). Minyak kelapa dibeli dari pengolah minyak kelapa di Ampenan Mataram.

Hidroksilaminolis. Prosedur Hidroksilaminolis yang digunakan merujuk pada prosedur yang digunakan Suhendra et al. (2005a), dengan sedikit modifikasi. Sejumlah minyak kelapa yang dilarutkan dalam heksana direaksikan dengan hidroksilamina hidroklorida yang telah dinetralkan dengan $\mathrm{NaOH} 6 \mathrm{~N}$ dan sejumlah enzim lipase dalam erlenmeyer $100 \mathrm{ml}$ bertutup. Campuran reaksi kemudian di inkubasi ke dalam water shaker batch dengan kecepatan guncangan 100 rpm. Asam lemak hidroksamik (ALH) yang terbentuk pada antarmuka air-heksana kemudian dipisahkan dari air dan lipase dengan penyaringan. Untuk memperoleh ALH padat, fraksi heksana didinginkan di dalam lemari pendingin $\left(<-5^{\circ} \mathrm{C}\right)$ selama lima jam dan kemudian disaring dan dibilas dengan heksana beberapa kali untuk menghilangkan sisa minyak. ALH yang terbentuk dikeringkan dalam desikator vakum di atas fosfor pentoksida selama 24 jam.

Karakterisasi produk. Analisis kualitatif dari gugus asam hidroksamik pada ALH dilakukan menggunakan FTIR spektroskopi (Perkin Elmer FTIR-Spectrum BX, USA). Komposisi asam lemak dalam ALH ditentukan menggunakan High-Performance Liquid Chromatography (HPLC) mengikuti prosedur yang dikembangkan oleh Gutnikov dan Streng (1991), yang dimodifikasi. HPLC yang digunakan adalah produk dari Waters HPLC-USA yang dilengkapi dengan berbagai piranti, yaitu Waters Delta-600 pump, Waters 600-controller, Waters-2487 Dual 1 Absorbance Detector dan Shimadzu CTO-6A column oven.

\section{HASIL DAN PEMBAHASAN}

Pengaruh Waktu Reaksi. Waktu reaksi adalah indikator kinerja enzim. Pengaruh waktu reaksi ini digunakan sebagai patokan untuk memperoleh waktu reaksi tersingkat dengan hasil terbaik. Penentuan waktu reaksi optimum ini juga bertujuan untuk meminimalisasi ekpansi proses yang berlebih (Yee et al. 1997). Gambar 1 menunjukkan bahwa 
waktu reaksi naik dengan cepat hingga 30 jam pertama. Di atas 30 jam reaksi tidak menunjukkan peningkatan yang berarti, hal ini kemungkinan disebabkan terbentuknya padatan dalam reaksi sehingga terjadi penghambatan transfer massa (mass-transfer limitations). Kemungkinan lain adalah tercapainya reaksi kesetimbangan, yaitu reaksi ke arah terbentuknya produk sama dengan reaksi terurainya produk sehingga konsentrasi produk tidak berubah.

Pengaruh Suhu Reaksi. Perubahan suhu reaksi dapat mempengaruhi aktivitas dan stabilitas enzim dan tentunya juga berpengaruh terhadap laju reaksi (Mc Gilvery \& Goldstein 1983). Gambar 2 memperlihatkan kenaikan rendemen pada kenaikan suhu dari $30^{\circ} \mathrm{C}$ ke $40^{\circ} \mathrm{C}$. Namun demikian, ketika suhu dinaikkan hingga $70^{\circ} \mathrm{C}$, randemen turun secara drastis. Hal ini kemungkinan disebabkan oleh terurainya (denaturing) lipase pada suhu di atas $40^{\circ} \mathrm{C}$.

Walaupun suhu optimum reaksi pada penelitian ini adalah $40^{\circ} \mathrm{C}$, namun pada scaling up, semua reaksi berlangsung pada suhu kamar, untuk Kota Mataram $30-34^{\circ} \mathrm{C}$. Pemilihan suhu kamar ini disebabkan selain untuk menghindari degradasi ikatan rangkap dari produk pada suhu tinggi juga dikarenakan kenaikan rendemen antara suhu 30 dan $40^{\circ} \mathrm{C}$ tidaklah besar, sehingga pelaksanaan reaksi pada suhu kamar dapat menghemat energi listrik.

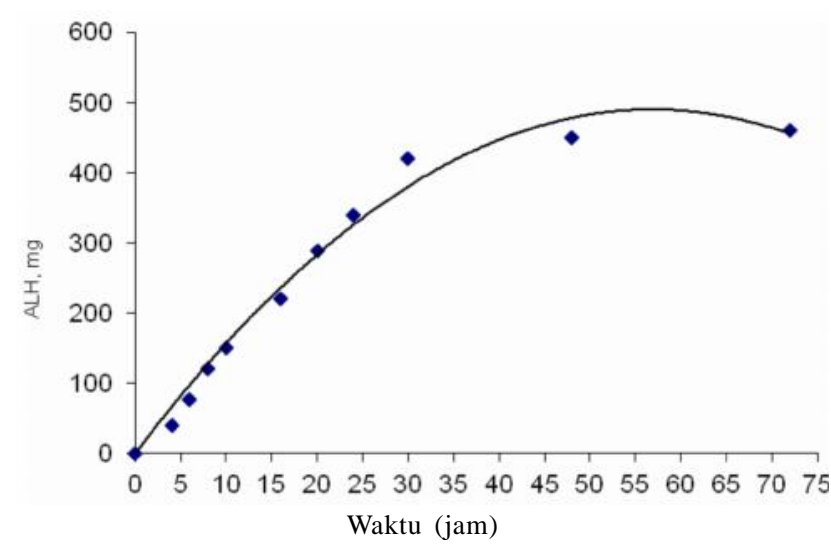

Gambar 1 Pengaruh waktu reaksi

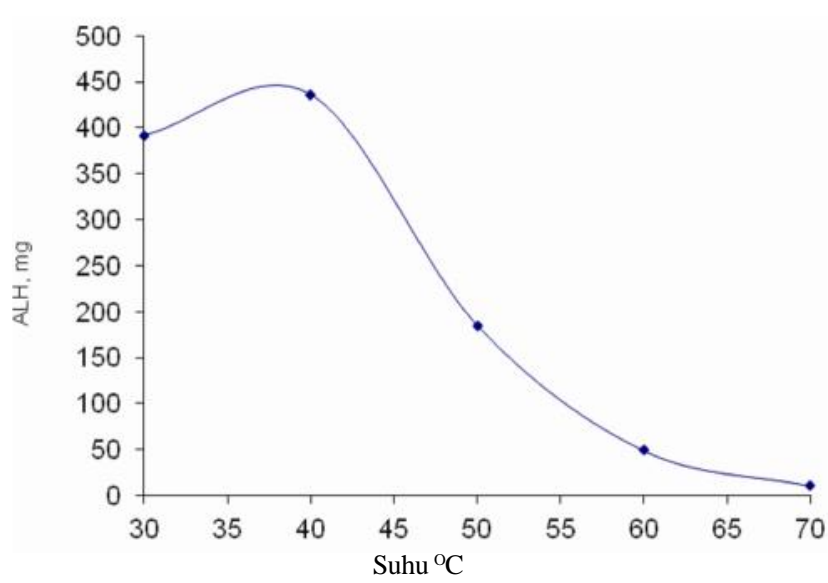

Gambar 2 Pengaruh suhu reaks

\section{Pengaruh Konsentrasi Hidroksilamina.}

Perbandingan optimum substrat yang digunakan adalah suatu yang penting dalam implementasi pada industri (Arcos et al. 1998). Gambar 3 menunjukkan adanya kenaikan randemen ALH dengan naiknya konsentrasi hidroksilamina. Hasil ini sesuai dengan hasil yang diperoleh Suhendra et al. 2005, pada sintesis ALH dari minyak kelapa sawit. Gambar 3 juga menunjukkan bahwa semakin tinggi konsentrasi hidroksilamina terjadi penurunan pada rendemen. Fenomena ini sesuai dengan hasil yang ditunjukkan oleh Vaysse et al. (1997), yang memperlihatkan terbentuknya inhibitor jika konsentrasi hidroksilamina cukup tinggi.

Pengaruh Jumlah Enzim. Untuk keperluan industri, maka jumlah enzim yang digunakan dalam reaksi diharapkan sekecil mungkin untuk memperoleh hasil sebanyak mungkin. Oleh karena itu, jumlah enzim adalah suatu yang sangat krusial dalam menekan ongkos produksi (production cost). Hasil penelitian ini (Gambar 4) menunjukkan bahwa jumlah enzim yang tinggi (perbandingan jumlah enzim : substrat diatas 30) tidak memberi kontribusi pada rendemen ALH.

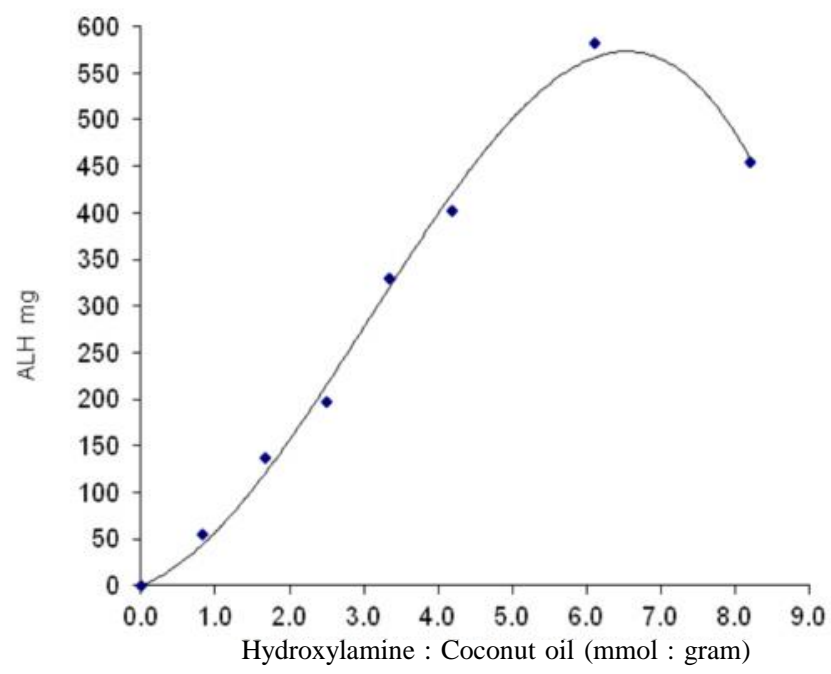

Gambar 3 Pengaruh konsentrasi hidroksilamina

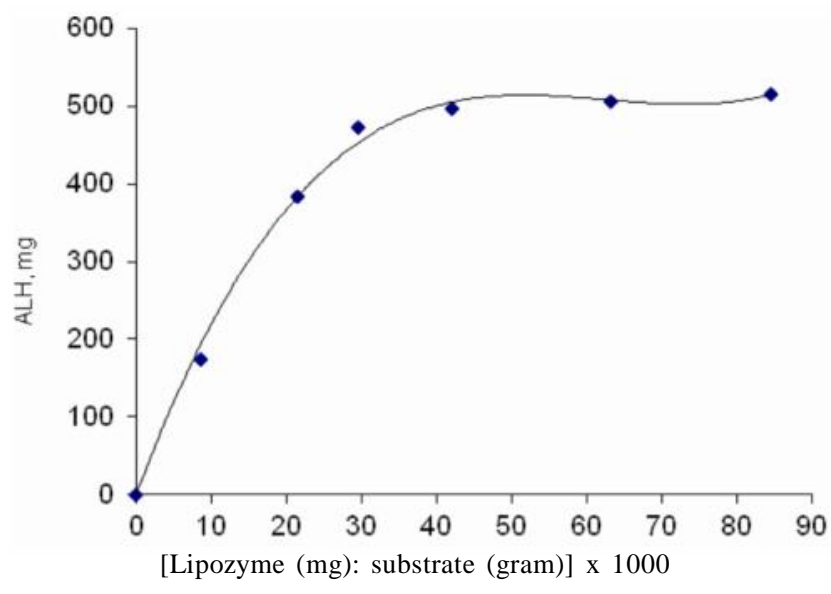

Gambar 4 Pengaruh jumlah enzim 
Karakterisasi ALH. FTIR Spektra. Spektrum FTIR dari substrat (minyak kelapa) dan produk (ALH) disajikan dalam Gambar 5. Pada spektrum minyak kelapa terlihat puncak kuat pada $2848 \mathrm{~cm}^{-1}$ dan $2916 \mathrm{~cm}^{-1}$ yang menunjukkan adanya gugus $\mathrm{C}-\mathrm{H}$ vibrasi ulur (stretching) dari alkil rantai panjang. Puncak ini didukung oleh puncak pada $1452 \mathrm{~cm}^{-1}$ yang merupakan puncak dari gugus $\mathrm{C}-\mathrm{H}$ vibrasi tekuk (bending) (Skoog et al. 1998). Puncak lain adalah pada $1740 \mathrm{~cm}^{-1}$ yang merupakan puncak khas dari gugus $\mathrm{C}=\mathrm{O}$ stretching. Adanya gugus $\mathrm{OH}$ dan $\mathrm{NH}$ pada produk menandakan terbentuknya ALH.

Spektrum ALH terlihat mirip dengan spektrum substrat, namun terlihat jelas perbedaannya, yaitu adanya gugus $\mathrm{OH}$ yang ditandai dengan adanya puncak pada $3426 \mathrm{~cm}^{-1}$ yang merupakan daerah khas untuk $\mathrm{OH}$ stretching dan adanya gugus NH yang ditandai dengan puncak pada $3264 \mathrm{~cm}^{-1}$ yang merupakan puncak khas N-H stretching. Puncakpuncak ini didukung oleh puncak pada $1662 \mathrm{~cm}^{-1}$ yang merupakan puncak khas untuk $\mathrm{C}=\mathrm{O}$ dari amida sekunder.

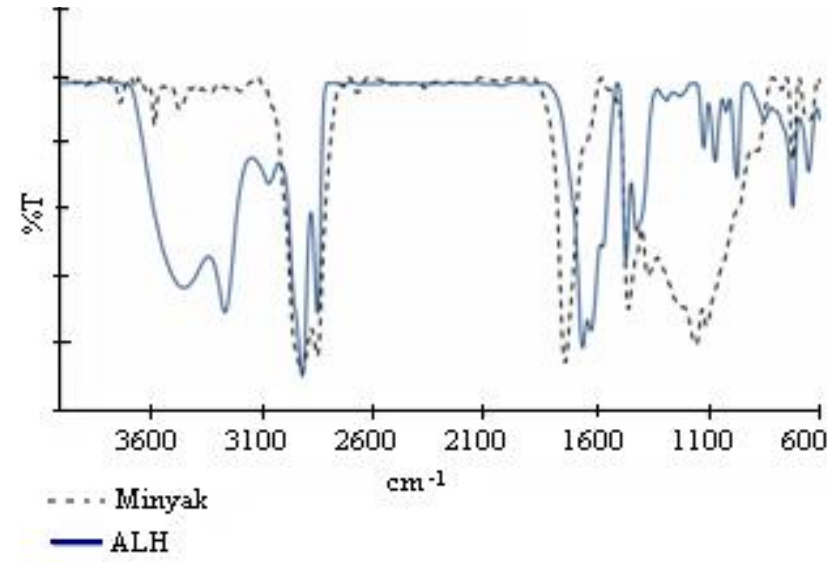

HPLC. HPLC adalah metode pemisahan yang akhirakhir ini banyak digunakan. Penggunaan yang luas disebabkan metode ini dapat digunakan untuk analisis kualitatif dan kuantitatif sekaligus. Tiap senyawa dalam campuran, pada kondisi yang diinginkan, mempunyai waktu elusinya (time retention) sendiri (analisis kualitatif) dan mempunyai luas area signal yang berhubungan dengan jumlah zat (analisis kuantitatif) tersebut (Meyer 1994).

Waktu retensi (retention time, $t_{R}$ ) dari suatu senyawa adalah khas untuk senyawa tersebut (Snyder \& Kirkland 1979). Oleh karenanya, jika diketahui harga $t_{R}$ dari suatu senyawa yang tidak diketahui (unknown compound) sesuai dengan harga $t_{R}$ dari senyawa standar yang diukur menggunakan kondisi yang sama, maka dapat dipastikan senyawa tersebut adalah sama. Komposisi asam-asam lemak hidroksamik dari minyak kelapa dapat dilihat pada Gambar 6. Pada gambar tersebut terlihat komposisi dari ALH yang telah dibandingkan dengan kromatogram standar, yaitu asam lauril hidroksamik (67,5\%), asam miristil hidroksamik $(20,9 \%)$, asam palmitil hidroksamik $(9,3 \%)$ dan asam stearil hidroksamik $(2,3 \%)$.

\section{SIMPULAN}

Penelitian ini telah berhasil mensintesis ALH dari minyak kelapa dengan katalis lipase komersial (lipozim). Kondisi optimum sintesis ALH dari minyak kelapa adalah waktu reaksi $30 \mathrm{jam}$, suhu reaksi $=\operatorname{suhu}$ kamar $\left(30^{\circ} \mathrm{C}\right)$, rasio Lipozim (mg): Substrat $(\mathrm{g})=29,5$, dan rasio Hidroklamin (mmol): Substrat $(\mathrm{g})$ adalah 6.

Gambar 5 Spektrum FTIR minyak kelapa dan ALH

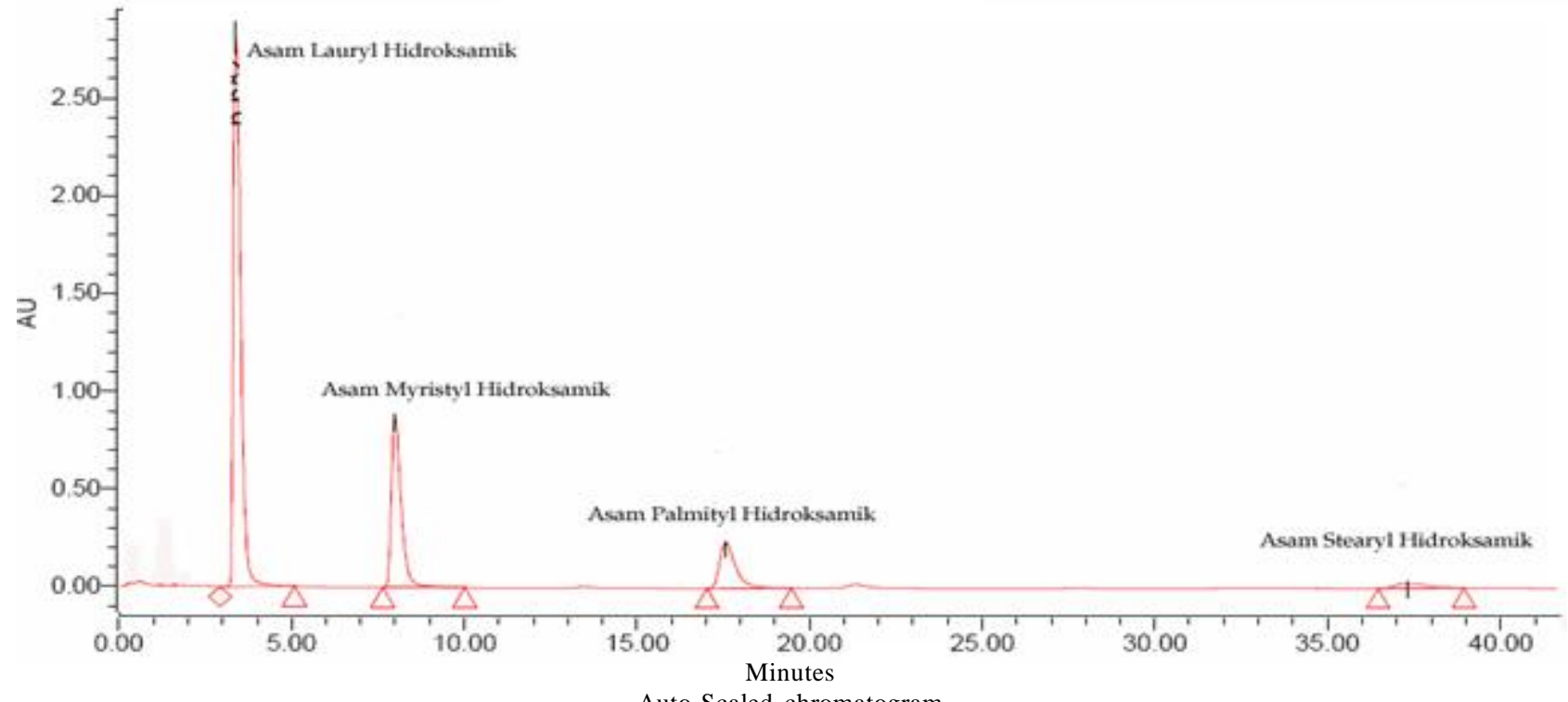




\section{UCAPANTERIMAKASIH}

Terima kasih diucapkan kepada Direktur DP2M Direktorat Jenderal Pendidikan Tinggi, Departemen Pendidikan Nasional yang telah mendanai penelitian ini melalui skim Penelitian Fundamental dengan Surat Perjanjian No: 003-SP.PFD./H18.12.2/PL/2009, Tanggal 18 April 2009.

\section{DAFTAR PUSTAKA}

Agrawal, Y.K \& Kaur, H. 1999. Poly( $\beta$-styryl) hydroxamic acids: synthesis and ion exchange separation of rear earths. React Funct Polym 39: 155-164.

Anandan, S.K., Ward, J.S., Brokx, R.D., Mark T.D. Bray, R., Patel D.V \& Yi Xiao, X. (2007). Design and synthesis of thiazole-5-hydroxamic acids as novel histone deacetylase inhibitors. Bioorg Med Chem Lett 17: 5995-5999.

Arcos, J.A., Barnabe, M \& Otero, C. 1998. Quantitative enzymatic production of 6-O-Acylglucose esters. Biotechnol Bioeng 57: 505-509.

Deng, H., Nanjo, H., Qian, P., Xia, Z., Ishikawa, I \& Suzuki, T.M. 2008. Corrosion prevention of iron with novel organic inhibitor of hydroxamic acid and UV irradiation. Electrochim Acta 53: 2972-2983.

Gutnikov, G \& Streng, J.R. 1991. Rapid high performance liquid chromatographic determination of fatty acid profiles of lipids by conversion to their hydroxamic acids. J Chromatogr 587: 292-296.

Holmes, J., Mast, K., Marcotte, P., Elmore, I., Li, J., Pease, L., Glaser, K., Morgan, D., Michaelides, M \& Davidsen, S. 2001. Discovery of hydroxamic acid inhibitors of tumor necrosis factor- $\alpha$ converting enzyme. Bioorg Med Chem Lett 11: 2907-2910.

Isha, A,. Suhendra, D., Yusof, N.A., Ahmad, M., Wan Yunus, W.M.Z \& Zainal, Z. 2007. Optical fiber chemical sensor for trace vanadium(V) determination based on newly synthesized palm based fatty hydroxamic acid immobilized in polyvinyl chloride membrane. Spectrochim Acta A 67: 1398-1402.

Kurzak, B., Kozlowski, A \& Farkas, F. 1992. Hydroxamic and amino hydroxamic acids and their complexes with metal ions. Coordin Chem Rev 114: 169-200.
Liu, Y.H., Lin, S.Y., Lee, C \& Hou, W.C. 2008. Antioxidant and nitric oxide production inhibitory activities of galacturonyl hydroxamic acid. Food Chem 109: 159-166.

McGilvery, R.W \& Goldstein, G.W. 1983. Rates of Enzymatic Reaction in Biochemistry: A Functional Approach. $3^{\text {rd }}$ Edition, London: W.B. Sounders Co., p. 296-307.

Meyer, V.E. 1994. Practical High-Performance Liquid Chromatography. Chichester: John Wiley \& Sons.

Pacco, A., Absillis, G., Binnemans, K \& Parac-Vogt, T.N. 2008. Copper(II) 15-metallacrown-5 lanthanide(III) complexes derived from 1-serine and 1-threonine hydroxamic acids. J Alloy Compd 451: 38-41.

Servat, F., Montet, D., Pina, M., Gazly, P., Arnaud, A., Ledon, H., Marcau, L \& Graillie, J. 1990. Synthesis of fatty hydroxamic acids catalyzed by the lipase of mucor meihei. $J$ Am Oil Chem Soc 67(10): 646-649.

Skoog, D.A., Holler, F.J \& Neiman, T.A. 1998. Principles of Instrumental Analysis, Fifth ed., Singapore: Thomson Learning Academic Resource Centre.

Snyder, L.R \& Kirkland, J.J. 1979. Introduction to Modern Liquid Chromatography, Toronto: John Wiley \& Sons.

Suhendra, D., Haron, M.J., Silong, S., Basri, M \& Wan Yunus, W.M.Z. 2006. Separation and preconcentration of copper(II) ion by fatty hydroxamic acids immobilized onto amberlite XAD- 4 Resin. Ind J Chem 6(2): 165-169.

Suhendra, D., Haron, M.J., Silong, S., Basri, M \& Wan Yunus, W.M.Z. 2005a. Enzymatic synthesis of fatty hydroxamic acids from palm oil. J Oleo Sci 54(1): 33-38.

Suhendra, D., Yeen, K.P., Haron, M.J., Silong, S., Basri, M \& Wan Yunus, W.M.Z. 2005b. Copper ion extraction by a mixture of fatty hydroxamic acids synthesized from commercial palm olein. Solvent Extr Ion Exc J 23(5): 713-723.

Vaysse, L., Dubreueq, E., Pirat, J.L \& Galzy, P. 1997. Fatty hydroxamic acid biosynthesis in aqoeous medium in the presence of the lipase-acyltransferase from candida parapsilosis. Journal of Biotechnology 53: 41-46.

Yee, L.N., Akoh, C.C \& Philips, R.S. 1997. Lipase PS-catalyzed transesterification of citronellyl butyrate and geranyl caproate: effect of reaction parameters. J Am Oil Chem Soc 74: 255-259.

Zamora, A. 2005. Fats, Oils, Fatty Acids, Triglycerides, http:// www.scientificpsychic.com/ fitness/fattyacids1.html, $(7 \mathrm{Mei}$ 2008). 